\title{
The Effects of Facial Recognition Payment Systems on Intention to Use in China
}

\author{
Lin-Lin Zhang ${ }^{1}$, Jing $\mathrm{Xu}^{2}$, Daim Jeong ${ }^{3}$, Tabe Ekouka ${ }^{4}$, and Ha-Kyun Kim ${ }^{5 *}$ \\ 1,2,3,4 Doctoral Student, 48513 Graduate School of Information Systems, Pukyong \\ National Univ., 45, Yongso-ro, NamGu, Busan, Korea \\ ${ }^{5}$ Professor, 48513 Division of Business, Pukyong National Univ., 45 Yongso-ro, \\ NamGu Busan, Korea \\ 1123126501@daum.net, 2strangerrr0301@gmail.com,3polo7336@naver.com, \\ ${ }^{4}$ elvis.tabe@yahoo.com, ${ }^{5 * k i m h k @ p k n u . a c . k r}$
}

\begin{abstract}
The world started the 4th industrial revolution based on technology in the IT field, and it is continuously developing. New technologies such as big data, Internet of Things, and health care have been applied to various fields. In particular, the fintech industry where new technologies are applied is undergoing rapid change. With the start of the 4th Industrial Revolution, new technologies began to be applied to various fields. Among them, face recognition technology was applied in fields such as customs, attendance, and payment, and the convenience was greatly improved. Today, the financial industry uses face recognition technology to start the era of face recognition payment services. This paper conducts an empirical analysis was conducted on how the characteristics of the face recognition payment system and innovation resistance affect the intention to use. Based on previous studies, face recognition payment system has the characteristics of convenience, reliability, security and non-contact. The collected data were analyzed by Smart PLS 2.0 using structural equations. The results of the study are as follows. First, among the features of the face recognition payment system, convenience, reliability and security have a negative effect on user innovation resistance. Second, among the features of the face recognition payment system, non-contact has a positive impact on user innovation resistance. Third, user innovation resistance has a negative effect on the intention to use.
\end{abstract}

Keywords: Face recognition, Convenience, Reliability, Security, Non-contact, Innovation resistance, Intention to use

\section{Introduction}

The world started the 4th Industrial Revolution based on technologies such as big data, and new technologies were applied to various fields. In particular, the Fintech industry to which new technologies are applied has undergone a change in the world.

Finland launched the world's first face recognition payment system "Uniqul" in 2013, and payment can be made only by recognizing the face through the camera. However, with the development of electronic financial transaction methods, personal information or personal

Article history:

Received (November 14, 2020), Review Result (December 19, 2020), Accepted (January 4, 2021)

JARR

Copyright (C) 2021 Global Vision Press (GV Press) 
privacy often leaks. Therefore, the convenience increases and the risks also increase [1]. Face recognition payment service is creating a new payment market, but it is not yet mature.

The purpose of this study is to provide information that companies can refer to in order to successfully spread face recognition payment service and reduce resistance to use.

\section{Theoretical background}

\subsection{Face recognition technology and payment system}

Face recognition technology is determines what kind of person a corresponding face is through automatic detection and analysis of a face area for an input still image or video including a face [2]. In the face recognition process, a person's face is scanned using a camera, and then analyzed as facial feature points such as eyes, mouth, and ears, and data is extracted [3]. There are two types of services that pay through face recognition. One is a mobile-based payment service. Mobile simple payment is a payment service that authenticates your account and pays expenses by recognizing your face through a camera instead of a password, without entering additional information whenever payment is required using an application [4]. Another is a payment platform based on a face recognition system. It first started in July 2013 at the Finnish startup Uniqul. When paying, just look at the camera on the POS screen. The payment system automatically links the consumer's face information with the personal account, so the entire transaction process can be completed within 5 seconds.

\subsection{Face recognition payment system characteristics}

With the development of convenient payment, people don't need wallets, cards, and cash, because they can easily pay only through mobile passwords or biometrics. According to the research on system quality research, it can be considered that system quality refers to the extent to which users use the system effectively, while convenience, reliability, security and response speed are factors that measure system quality [5]. Face recognition has non-contact advantages over other methods when studying the status and prospects of biometrics. In this paper, the quality characteristics of the face recognition payment system were selected as convenience, reliability, security, and non-contact.

Convenience has utility related to use such as convenience of movement, convenience of time, and convenience of operation [6]. Reliable means positive expectations for the target, which greatly affects satisfaction with the service and the intention to use it continuously, contributing to the profitability of the company [7]. Security is the degree of personal information or financial transaction-related information system management in the use of financial technology payment service processes without leakage [8]. It defines the degree to which you believe that personal or financial information will be protected without leakage in the process of using new technology. Non-contact means that the user can continue to operate while keeping a certain distance from the machine without physical contact with the machine [9].

\subsection{Innovation resistance}

Acceptance of innovation changes the existing way of life, and is accompanied by negative feelings such as fear, uncertainty, doubts, as well as expectations for the changes that innovation will bring [10]. Some people believe that innovation resistance is a tendency not to accept innovation, and it is a normal reaction of a specific individual when facing new 
changes. This resistance to innovation stems from the uncertainty and fear of new changes[11].

\subsection{Intention to use}

In the field of management information systems, two factors, intention to use and actual usability, have been considered in researching individual users' attitudes related to the adoption of information technology [12]. Intention to use is a psychological decision made when an innovative product or service feels convenient, easy to use, and useful.

\section{Research model and research hypothesis}

\subsection{Research model}

From the viewpoint that the features of the face recognition payment system will have a great influence on the customer's intention to use, the features of the face recognition payment system, convenience, reliability, security, and non-contact were selected as variables. In this study, the purpose of this study is to empirically study the tolerance that the characteristic factors of the face recognition payment system influence the customer's intention to use. For this, a research model as shown in [Figure 1] was designed.

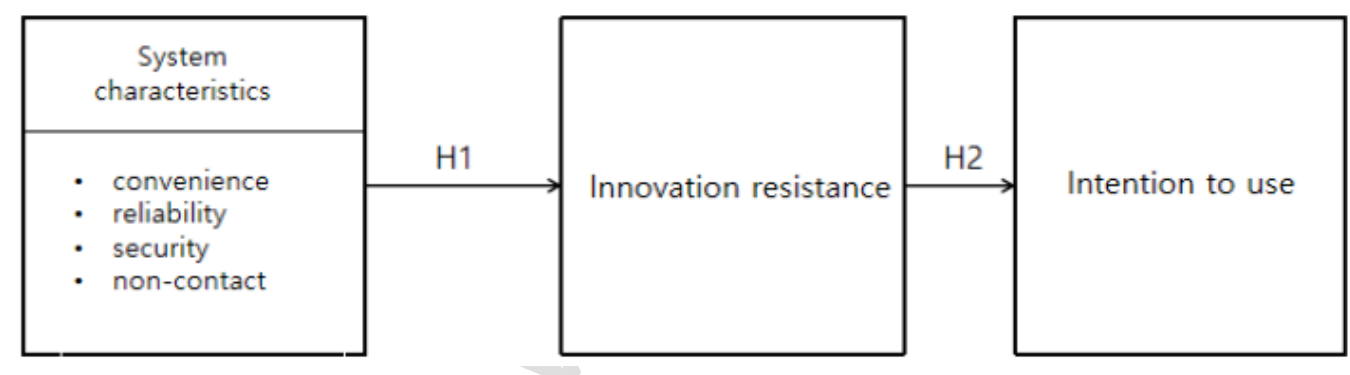

Figure 1. Research model

\subsection{Research hypothesis}

Information System Success Model is organized information characteristics and system characteristics. These will affect customers' intention and satisfaction. And take convenience, safety, reliability, stability and response speed as the characteristic factors of the system. It is proposed in the research that face recognition has non-contact characteristics [13]. The following hypothesis was established.

H1-1: Among the features of the face recognition payment system, convenience has a negative (-) effect on innovation resistance.

H1-2: Among the features of the face recognition payment system, reliability has a negative (-) effect on innovation resistance.

H1-3: Among the characteristics of the face recognition payment system, security has a negative (-) effect on innovation resistance.

H1-4: Among the features of the face recognition payment system, non-contact has a positive (+) effect on innovation resistance.

Innovation resistance is a kind of uncertainty, manifested as uncertainty and doubt about novelty, and they believe that innovation resistance has an important influence on the communication and use intention of innovation. The following hypothesis was established 
H2: Innovation resistance has a negative (-) effect on the intention to use.

\subsubsection{Operational definition and measurement of variables}

It was used to verify the structural model for data analysis. The characteristics of face recognition payment system is analyzed by based on previous studies. The question of each concept is scaled by question. It was composed on the Likert 5-point scale; very not so (1), it is not (2), normal (3), yes (4) and very yes (5).

\section{Empirical analysis}

\subsection{Collect data}

This research conducted an empirical analysis through questionnaires. The questionnaire survey method is to conduct an online survey in cooperation with a Chinese survey service company.

The survey was conducted on Chinese consumers. The survey started on August 19, 2020, lasted 21 days, and distributed 198 copies. In the questionnaire survey, males accounted for $46.46 \%$, females accounted for 53.54\%, and the 20-29 age group accounted for the largest proportion, accounting for $43.94 \%$. Undergraduates with education level accounted for $82.83 \%$, and students accounted for $40.91 \%$. Most studies on the intention of adopting innovative technology products were generally accepted by young consumers. Therefore, this analysis is mainly for those who are 20 29 years old with a college degree or above.

\subsection{Data analysis method}

This article uses SPSS 22.0 as the basic statistics and uses the structural equations to analyze Smart PLS 2.0 (partial least squares). Basically, reliability should be Cronbach's Alpha 0.7 or higher. The validity is divided into concentration validity and discriminant validity. Concentration validity examines the factor loading value, component reliability (CR) and variance extraction index value (AVE) of each factor. In general, the factor loading value is 0.6 or more, the component reliability value is 0.7 or more, and the variance extraction index value is 0.5 or more. to be. As a result of comparing the square root of the variance extraction index value with the correlation coefficient, the variance extraction index value is greater than the vertical and horizontal correlation coefficient values, so there is no problem with the discriminant validity.

\subsection{Verification of the structural model}

In this study, PLS was adopted as the data analysis method in consideration of the characteristics of the study such as theoretical robustness, the number of samples, and selfdevelopment of the questionnaire. If the $\mathrm{R}^{2}$ value is 0.26 or more, the degree of fitness is high, and if it is 0.26 to 0.13 , the degree of fitness is expressed as medium, and if it is less than 0.13 , the degree of fitness can be expressed as low. Innovative resistance (0.593) of the component value can be evaluated as high, and intention to use (0.287) can be evaluated as high.

Table 2. Reliability and internal consistency

\begin{tabular}{|c|c|c|c|c|}
\hline Variable name & $\begin{array}{c}\text { Factor } \\
\text { Loading }\end{array}$ & AVE & $\begin{array}{c}\text { Composite } \\
\text { Reliability }\end{array}$ & $\begin{array}{c}\text { Cronbach's } \\
\text { Alpha }\end{array}$ \\
\hline
\end{tabular}




\begin{tabular}{|c|c|c|c|c|c|}
\hline \multirow{3}{*}{ Convenience } & CON1 & 0.926 & \multirow{3}{*}{0.802} & \multirow{3}{*}{0.924} & \multirow{3}{*}{0.876} \\
\hline & $\mathrm{CON} 2$ & 0.934 & & & \\
\hline & CON3 & 0.823 & & & \\
\hline \multirow{3}{*}{ Reliability } & RES1 & 0.923 & \multirow{3}{*}{0.858} & \multirow{3}{*}{0.948} & \multirow{3}{*}{0.917} \\
\hline & RES2 & 0.946 & & & \\
\hline & RES3 & 0.910 & & & \\
\hline \multirow{3}{*}{ Security } & SEC1 & 0.922 & \multirow{3}{*}{0.865} & \multirow{3}{*}{0.951} & \multirow{3}{*}{0.922} \\
\hline & SEC2 & 0.942 & & & \\
\hline & SEC3 & 0.927 & & & \\
\hline \multirow{2}{*}{ Non-contact } & NOC1 & 0.906 & \multirow{2}{*}{0.803} & \multirow{2}{*}{0.891} & \multirow{2}{*}{0.756} \\
\hline & NOC2 & 0.887 & & & \\
\hline \multirow{3}{*}{$\begin{array}{l}\text { Innovation } \\
\text { resistance }\end{array}$} & INR1 & 0.933 & \multirow{3}{*}{0.880} & \multirow{3}{*}{0.956} & \multirow{3}{*}{0.932} \\
\hline & INR2 & 0.959 & & & \\
\hline & INR3 & 0.921 & & & \\
\hline \multirow{3}{*}{ Intention to use } & IOU1 & 0.925 & \multirow{3}{*}{0.838} & \multirow{3}{*}{0.939} & \multirow{3}{*}{0.903} \\
\hline & IOU2 & 0.940 & & & \\
\hline & IOU3 & 0.880 & & & \\
\hline
\end{tabular}

Table 3. Correlation and discriminant validity

\begin{tabular}{|c|c|c|c|c|c|c|c|}
\hline & AVE & Convenience & Responsibility & Security & $\begin{array}{c}\text { Non- } \\
\text { contact }\end{array}$ & $\begin{array}{c}\text { Innovation } \\
\text { resistance }\end{array}$ & $\begin{array}{c}\text { Intention to } \\
\text { use }\end{array}$ \\
\hline Convenience & 0.802 & 0.896 & & & & & \\
\hline Reliability & 0.858 & 0.814 & 0.926 & & & & \\
\hline Security & 0.865 & 0.743 & 0.730 & 0.930 & & & \\
\hline Non-contact & 0.803 & -0.272 & -0.285 & -0.257 & 0.896 & & \\
\hline $\begin{array}{c}\text { Innovation } \\
\text { resistance }\end{array}$ & 0.880 & -0.537 & -0.544 & -0.510 & 0.656 & 0.938 & \\
\hline $\begin{array}{c}\text { Intention to } \\
\text { use }\end{array}$ & 0.838 & 0.807 & 0.809 & 0.819 & -0.331 & -0.536 & 0.915 \\
\hline
\end{tabular}

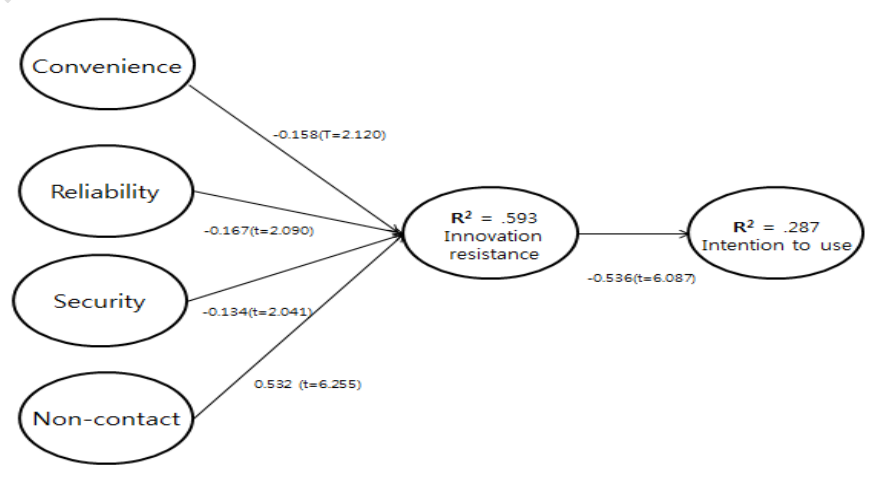

Figure 2. The results of research model 


\subsection{Analysis of test result}

The analysis of the research hypothesis put forward in this research and the same results as in [Table 4] were obtained. Looking at the verification results shown in [Table 4], all assumptions have been accept.

Table 4. Hypothesis test result summary

\begin{tabular}{|c|c|l|l|l|l|}
\hline & Cause variable & Result variable & Path coefficeient & T-value & Result \\
\hline H1 & Convenience & Intention to use & -0.158 & 2.120 & Accept \\
\hline H2 & Reliability & Intention to use & -0.167 & 2.090 & Accept \\
\hline H3 & Security & Intention to use & -0.134 & 2.041 & Accept \\
\hline H4 & Non-contact & Intention to use & 0.532 & 6.255 & Accept \\
\hline H5 & $\begin{array}{c}\text { Innovation } \\
\text { resistance }\end{array}$ & Intention to use & -0.536 & 6.087 & Accept \\
\hline$t=1.960^{* *}(P<0.05)$ &
\end{tabular}

\section{Conclusion}

The research results of this paper are as follows.

Hypothesis 1; the characteristics of face recognition payment system and the resistance to innovation was all adopted. In other words, in face recognition payment services, convenience, reliability and security have a negative effect on innovation resistance, while non-contact have a positive effect on innovation resistance. Hypothesis 2; innovation resistance and customer intention to use was also adopted. In other words, innovation resistance has a negative effect on customer intention to use.

Based on the results of this study, the following implications can be presented.

First, it is found that the convenience, reliability and security of the face recognition payment system have a negative effect on innovation resistance. In other words, the more convenient the face recognition payment system is than the existing payment services, the higher the reliability of the technology or enterprise provided, or the more secure the system is in protecting personal information and transaction information, the greater the resistance to innovation low.

Second, from the results, the higher the non-contact of the face recognition payment system, the higher the resistance to innovation. Moreover, non-contact has a great impact on innovation resistance. The convenient payment service uses face recognition technology to simplify identity verification. Although the verification time and steps are reduced, but it is found people worry about face information being collected and analyzed in a non-contact manner when performing face recognition.

Third, innovation resistance will have a negative impact on usage intention. In other words, the higher people's resistance to emerging technologies or services, the lower their willingness to use them.

The limitation of this article is that it only studies the influence of innovation resistance and intention to use from the aspect of system characteristics. In the future, we will conduct detailed research on factors such as innovation characteristics and consumer characteristics based on the innovation resistance theory. 


\section{References}

[1] M. Kim and D. Son, "The Effect of Privacy and Trust Factors in Fintech Service, Korea Internet Electronic Commerce Association,” vol.20, no.1, pp.87-98, (2020)

[2] H. Kim, J. Moon, and J. Park, "Research trends for deep learning-based high-performance face recognition technology, electronic communication trend analysis," vol.33, no. 4, pp.43-53, (2018)

[3] J. Lee, "Changes in society according to facial recognition technology, magazine of the SAREK," vol.49, no.3, pp.90-91, (2020)

[4] H. Lee, S. Park, M. Sung, C. Sun, M. Jeong, Y. Park, and J. Yun, "A comparison of user perceptions of user interface security features within mobile easy payment system," The HCI Society of Korea, pp. 503-511, (2018)

[5] M. Choi and S. Song, "A study on the influence of system quality characteristics of mobile payment service on discontinuance intention,” J Korean Soc Qual Manag, vol.46, no.3, pp.625-640, (2018)

[6] H. Gao, "A study on intention to use fintech service: Focusing on fintech users in Korea and China," Ph.D. dissertation, Keamyung University, (2019)

[7] J. Choi, "Personal and system factors for trust in mobile payment system," Journal of the Korean Contents Association Conference, pp.195-196, (2017)

[8] H. Son, "The effect of factors of fintech service on the trust and innovative resistance," The Journal of Internet Electronic Commerce Research, vol.19, no.5, pp.146-161, (2019)

[9] Y. Zhang, J. Ma, H, Park, Factors Affecting the Usage of Face Recognition Payment Service, Journal of the Korea Contents Association, vol.19, no.8, pp.490-499, (2019)

[10] J. Shin, and S. Lee, "A study of intention to use wrist-worn wearable devices based on innovation resistance model - focusing on the relationship between innovation characteristics," Consumer Characteristics, and Innovation Resistance, Journal of the Korea Contents Association, vol.16, no.6, pp.123-134, (2016)

[11] G. Jang, H. Jang, "The relationship of mobile payment service using value and innovation resistance," Continuous Use Intention, Journal of Digital Contents Society, vol.19, no.11, pp.2203-2210, (2018)

[12] J. Moon, "Exploration of factors affecting intention to use mobile banking, business and information research," vol.38, no.1, pp.103-120, (2019)

[13] H. Jang, "A study on personal authentication technology using multiple biometrics method," Dankook University Graduate School, (2019) 
This page is empty by intention. 